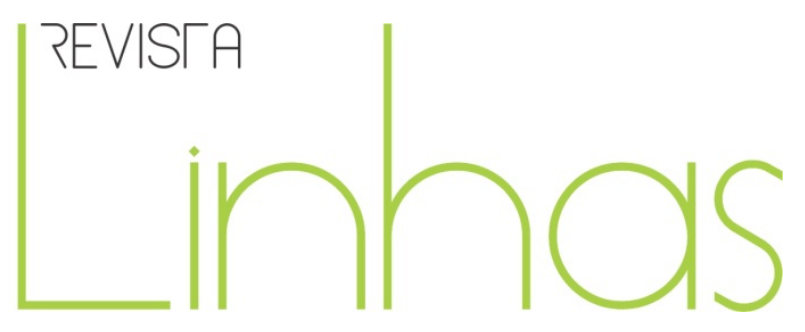

\title{
Reflexões sobre o ensino a distância à luz da noção de contrato didático
}

\begin{abstract}
Resumo
Em virtude do crescimento do número de cursos de formação de professores a distância torna-se necessária uma maior investigação sobre esta modalidade. Neste trabalho refletimos sobre as novas relações didáticas estabelecidas utilizando a noção de Contrato Didático, apontamos diferenças entre os contratos estabelecidos nas modalidades: presencial e a distância, e levantamos questões para investigação. Esta reflexão foi feita a partir do modelo semipresencial adotado pela Universidade Federal de Santa Catarina (UFSC) em seus cursos. Entendemos que o aprofundamento dos pontos levantados neste trabalho pode auxiliar o desenvolvimento de novos materiais e metodologias para esta modalidade, independente do modelo adotado.
\end{abstract}

Palavras-chave: Ensino a distância; Ensino presencial; Relações didáticas; Contrato didático.
Frederico Firmo de Souza e Cruz

Doutor em Física pela Universidade de São Paulo - USP fred@fsc.ufsc.br

\section{Paulo José Sena dos Santos} Doutor em Física pela Universidade Federal de Santa Catarina - UFSC psena@fsc.ufsc.br

Sônia Maria Correa de Souza e Cruz Doutora em Educação em Ciências pela Universidade Federal de Santa Catarina - UFSC sonia@fsc.ufsc.br

\section{Para citar este artigo:}

CRUZ, Frederico Firmo de Souza e; SANTOS, Paulo José Sena dos; CRUZ, Sônia Maria Correa de Souza e. Reflexões sobre o ensino a distância à luz da noção de contrato didático. Revista Linhas, Florianópolis, v. 15, n. 28, p. 345-369, jan./jun. 2014.

\section{DOI: $10.5965 / 1984723815282014345$}

http://dx.doi.org/10.5965/1984723815282014345 


\title{
Reflexions about distance education and didactic contract
}

\begin{abstract}
In this paper we investigated the didactic relations that are established between students, teachers, tutors and the knowledge in the Distance Education context. For this analysis we depart from the very notion of Didactic Contract pointing out differences between this contract in traditional presential school and the distance education scenario. The analysis was based on the semipresential model adopted by the Federal University of Santa Catarina (UFSC), nevertheless it points out new questions for further investigations and some of the conclusions are not model dependent and can be helpful in the improvement and the proposition of new methodologies and didactic materials for Distance Education courses.
\end{abstract}

Keywords: Distance education; Presential education; Didactic relations; Didactic contract. 


\section{Introdução}

Embora a modalidade de Ensino a Distância, EAD, seja antiga, os avanços nas tecnologias de informação e nas comunicações geraram um grande salto qualitativo e quantitativo. A sua implantação no momento atual se difundiu muito pelo mundo, dentro e fora das instituições escolares. Porém, apesar dos avanços e da presença de novos instrumentos didáticos, a modalidade continua enfrentando resistências, devido, em grande parte, a quebras com relação a um paradigma fundamental da educação escolar que é o professor presencial e a sala de aula. No paradigma vigente, a tripla, professor, sala de aula e aluno, se harmoniza de forma orgânica com os materiais e instrumentos didáticos tradicionais, com a estrutura, com a organização escolar, com a organização espacial e temporal das escolas e com a formação dos professores. Toda esta organicidade naturaliza o paradigma vigente e gera resistências e obstáculos à implantação de inovações no ensino. Enfatizamos que as resistências não se limitam ao ensino a distância.

A modalidade de EAD traz em seu bojo a necessidade intrínseca de inovação. Exige o uso sistemático e orgânico de novos instrumentos didáticos, o que por sua vez exige a criação de novos materiais, a inserção de novas linguagens, novas formas de representação, novas formas de comunicação e algumas mudanças de concepção. Como disse Jacquinot (1993), as novas formas de comunicação desafiam a distância e tentam suprimir a ausência e relativizar o espaço e o tempo.

O ensino a distância cria um novo cenário, no qual velhos e novos personagens estabelecem uma nova dinâmica para as relações didáticas. Enquanto no ensino tradicional as relações didáticas se dão essencialmente dentro da sala de aula e envolvem basicamente o professor, o aluno e o conhecimento, no EAD o cenário é mais complexo, pois o processo se desenrola essencialmente fora da sala de aula, através de novos meios de comunicação, utilizando novas linguagens e a ação educativa é compartilhada entre professores e tutores. As relações com alunos e outros são mediados por plataformas de comunicação ou de forma mista quando a modalidade é semipresencial. Todas estas mudanças tornam a modalidade uma fonte imensa de reflexão e perguntas. Neste 
trabalho queremos focalizar nossa reflexão sobre o desenvolvimento das relações didáticas dentro deste novo cenário. Em nossas reflexões nos baseamos em categorias da Didática da Matemática desenvolvidas por Brousseau, Chevallard, Jonnaert e Borght e buscamos, sobretudo, levantar marcos, que nos permitam pontuar de forma mais precisa questões de investigação sobre esta modalidade.

Segundo Brousseau (1986), um dado conhecimento pode ser caracterizado por uma ou mais situações que conservam o seu sentido e significado fundamental. Estas situações são em geral situações adidáticas, pois estão fora do alcance do aluno. Através de um trabalho de transposição, o professor transforma estes conhecimentos em conhecimento escolar, isto é, em conhecimento a ser ensinado, que é explorado em uma série de atividades, problemas, tarefas, materiais que configuram uma situação didática, cujo objetivo é torná-lo acessível e permitir no processo de ensino aprendizagem que este conhecimento se torne um saber do aluno. Para que este processo ocorra, as responsabilidades do professor e do aluno são acertadas num contrato didático, que, diferentemente dos contratos usuais, tem algumas regras explícitas, e muitas regras implícitas e que se modifica à medida que aluno evolui na sua relação com o saber. Neste processo, cabe ao professor projetar e planejar as atividades e materiais que se concernem a estes conhecimentos que vão compor a situação didática. Cabe ao aluno cumprir as tarefas e atividades. No contrato, o professor se responsabiliza pela transposição didática e pela escolha de situações e o aluno confia que estes conhecimentos, singularizados pela particular escolha de situações didáticas, o levem posteriormente a estar instrumentalizado, tecnicamente, teoricamente e conceitualmente para adquirir conhecimentos e/ ou interpretar e significar problemas e questões típicas de situações adidáticas. Neste modelo, a situação didática se refere a uma transposição de uma situação adidática fundamental. A transposição subtrai ao aluno uma parcela de situações e conhecimentos associados ao conhecimento fundamental, isto é, a transposição de forma consciente e intencional, deixa de fora parte do saber sábio, mas pretende que o aluno em fase posterior possa adquiri-lo e interpretálo de acordo com a cultura e a ciência de sua época. Segundo esta visão, o processo de aprendizagem não pode ser completo sem a devolução do que foi subtraída a situação 
adidática. Esta situação, pela própria natureza, deve ser devolvida ao aluno quando este, devidamente instrumentalizado, se sente capaz de então romper o contrato com o professor e assumir a responsabilidade pessoal de enfrentar a situação adidática, problematizando e adquirindo tal conhecimento. Portanto, o contrato didático gerencia as relações professor-aluno essencialmente nas situações didáticas, mas se modifica com o desenrolar do processo. As modificações devem ser ditadas pela relação aluno-saber e o planejamento didático deve sempre projetar a ruptura, quando o aluno se torna capaz de buscar autonomamente a compreensão e os significados de situações adidáticas. Segundo Brousseau projetar o caminho para situações adidáticas é quase a definição de ensinar, e saber enfrentá-las é uma boa definição do que significa aprender.

No que segue vamos explorar este modelo de Brousseau na reflexão sobre cursos a distância no formato semipresencial adotado na Universidade Federal de Santa Catarina (UFSC). Neste formato as vagas são oferecidas em polos distribuídos pelo estado. Os polos são locais onde os alunos têm acesso garantido à midiateca, a computadores, equipamentos para a realização de videoconferências, salas de estudo, assim como a suporte técnico, administrativo e educacional. Os estudantes devem se deslocar aos polos sempre que forem marcadas atividades obrigatórias (encontros presenciais com os professores, videoconferências, avaliações, etc.) e quando tiverem alguma necessidade (orientação, material bibliográfico, etc.).

\section{Os novos papéis do professor}

Na educação tradicional o professor é a figura central na transposição do saber estabelecido (saber sábio) para o saber escolar. Cabe ao professor escolher os conteúdos, as técnicas e as teorias e realizá-las em situações didáticas previamente preparadas. O professor em sala de aula não apenas expõe um conteúdo, mas define, a partir de suas escolhas e critérios de avaliação, o saber a ser ensinado. Obviamente este conteúdo se baseia no que já foi institucionalmente acordado como conhecimento escolar relevante. Na sua relação com os alunos o professor acompanha, aconselha e orienta, visando o desenvolvimento da relação aluno-saber. Sua presença e contato 
direto clarificam para o aluno as regras de um contrato didático que define as responsabilidades do aluno e visa promover a relação aluno-saber. O professor assume a responsabilidade de promover o desenvolvimento da relação entre aluno e conhecimento e cabe ao aluno, seguindo as regras (frequentemente implícitas) do contrato didático, a responsabilidade de cumprir as tarefas e atividades propostas. Mas, sobretudo, o professor deve compreender o paradoxo didático, isto é, deve utilizar o contrato visando sua ruptura, deve visar o que Brousseau chama de devolução. Se por um lado as situações didáticas usuais se valem de problemas, questões, exercícios, textos e atividades especialmente montados para aprendizagem de determinados conteúdos e conceitos, a aprendizagem se dá quando o aluno extrapola a singularidade das atividades didáticas propostas, e passa a compreender, interpretar e utilizar este conhecimento para tratar situações outras que não as didáticas. O professor acompanha neste sentido a dinâmica da sala de aula e dos alunos, ora vigilante com relação ao cumprimento do contrato, ora criando passos para a sua ruptura. Na educação tradicional o professor também é o principal intérprete e ligação com a instituição. Suas atividades ao planejar, escolher conteúdos, formas, técnicas e teorias, e meios, como livros, sistema avaliativo, etc., refletem a instituição. O professor personifica a cultura institucional.

Alguns pesquisadores, como Keegan (1983) afirmam que no EAD quem ensina é a instituição. Belloni (2002) chama a atenção para o compartilhamento da ação educativa, que transforma o professor em uma entidade coletiva. O professor não é neste sentido uma pessoa, mas um coletivo com múltiplas funções. Ele torna-se responsável, pela concepção dos cursos e materiais, pelo planejamento de atividades, tarefas, pela organização espacial e temporal, pela distribuição destes materiais pela administração acadêmica; e tem ainda a responsabilidade pelo aconselhamento do estudante durante o processo de aprendizagem e pela avaliação.

Estas funções estão distribuídas por um conjunto de profissionais: designers instrucionais, designers gráficos, analistas de sistema, gerenciadores de plataformas, especialistas em software educacional e especialistas em tecnologias da informação e comunicação e tutores. Além das funções acima, Belloni (2002) ainda apresenta o tecnólogo educacional, que seria responsável pela resolução das dificuldades de 
integração, já que seu papel estaria relacionado à segurança da transposição do discurso escrito pelo professor/autor para as linguagens adequadas aos suportes técnicos.

A introdução das novas tecnologias de informação e comunicação permitem hoje ações que podem quase simular a presença de um professor num dado ambiente, no entanto, estas mesmas tecnologias exigem o desenvolvimento de novas competências e criam ambientes distintos de uma sala de aula.

As novas tecnologias trazem novas linguagens, novas formas de representação, estabelecem: novos saberes, novas atividades, novas tarefas e transformam o conteúdo a ser ensinado. Por exemplo, as linguagens gráficas possibilitam a criação de novas representações pictóricas, a computação algébrica ou numérica e as simulações possibilitam explorar qualitativa e quantitativamente teorias e modelos ou mesmo conceitos de forma mais profunda tornando acessível novos significados. Isto permite ampliar o número de situações que se referem a um mesmo objeto de ensino. Todos estes aspectos geram novas atividades, novas tarefas e novos conhecimentos que antes estariam fora do escopo, e que limitavam a transposição didática. Obviamente estes avanços também influenciam a modalidade presencial, porém é na modalidade a distância que eles são naturalmente necessários. A modalidade a distância exige lidar com estas inovações e não se restringe à ausência física do professor e da sala de aula, pois redefine papéis e parceiros na ação educativa, redefine o saber a ser ensinado, estabelece, em outras bases, a relação do professor com o saber, do aluno com o saber e da instituição com o saber.

As ações de planejamento, organização e transposição são agora compartilhadas com vários sujeitos que constituem o professor coletivo. Isto traz modificações significativas, mas não eliminam a figura central do professor. O objetivo do planejamento e da organização não é mais a sala de aula, mas sim a concepção de materiais e atividades que devem ser pensadas em conjunto com os dispositivos didáticos. O planejamento deve levar em conta os dois momentos do contrato didático. Isto é, o planejamento deve desenvolver situações didáticas que, mesmo na ausência da sala de aula, sejam efetivas no processo de aprendizagem do conhecimento escolar e também projetar situações adidáticas que favoreçam a devolução e a responsabilização 
do aluno no seu processo próprio de aprendizagem.

O ponto mais crítico do ensino a distância é o acompanhamento das modificações naturais das relações didáticas durante o processo de ensino aprendizagem. No ensino tradicional, a sala de aula é um local privilegiado para este acompanhamento. Na sala de aula, o professor e os alunos estabelecem o contrato didático com suas regras explícitas e implícitas e de forma natural as modificações no contrato vão ocorrendo através da própria dinâmica da sala. O acompanhamento é direto e mútuo, alunos e professores participam segundo suas responsabilidades nas modificações até a ruptura. Portanto, é natural se perguntar: como acompanhar o desenrolar do contrato didático sem a sala de aula? Como o professor e sua equipe vão detectar os sinais indicando necessidades de mudança e/ ou aceitação das regras explícitas e implícitas do contrato? Neste contexto, o tutor pode desempenhar um papel significativo devido ao maior contato com alunos o que indica a importância de investigar o papel dos tutores na dinâmica do contrato didático.

\section{Surge um novo parceiro: o tutor}

Segundo Maggio (2001), nas perspectivas tradicionais da modalidade a distância, era comum sustentar que o tutor direcionava, apoiava a aprendizagem dos alunos, mas não ensinava. A mediação ficava a cargo dos materiais, cujo desenvolvimento concluía-se com uma proposta de avaliação consistente com a proposta de ensino. Nesta perspectiva, a tradição indica que a tarefa do tutor consiste em assegurar o cumprimento dos objetivos, oferecendo apoio, sendo responsável pelo controle e ajuste do processo. Portanto, o papel do tutor seria o de um "acompanhante do sistema". Seria um instrumento para difundir as regras explícitas do contrato didático e assegurar o seu cumprimento.

Apesar da clara tentativa de definir os papéis do professor e do tutor como diferentes, o compartilhamento da ação educativa e a maior presença do tutor faz com que o mesmo desempenhe atividades similares à do professor presencial, porém dentro de um cenário distinto. Litwin (1994) enfatiza que a ideia de distância não se refere 
apenas à presença física, mas, sobretudo a não existência de aulas regulares. Diferentemente do professor presencial, que sabe que o aluno será "obrigado" a estar presente na próxima aula, o tutor não sabe se o aluno estará presente na próxima tutoria, ou se voltará a consultá-lo.

Segundo Litwin (1994), o tutor deve ter consciência que o sentido didático de cada intervenção é diferente, distinguindo-se em função de três dimensões de análise:

Tempo: ele não pode dizer "amanhã continuaremos", pois os alunos podem não voltar a assistir a tutoria, ou consultar o tutor.

Oportunidade: o momento no qual deve tornar manifesto como pensam os especialistas no âmbito do campo disciplinar.

Risco: aparece como consequência de privilegiar a dimensão tempo (escasso) e não aproveitar as (escassas) oportunidades, uma vez que no ensino a distância a compreensão parcial pode converter-se em uma compreensão errônea.

Estas colocações de Litwin deixam claro que mesmo havendo o contato presencial, e/ ou virtual, isto se dá de forma diferente da tradicional, pois não há a continuidade da sala de aula. Podemos nos perguntar se o tutor é outra faceta do professor coletivo, ou se o tutor é um novo elemento. Um elemento que modifica de forma substancial o triângulo didático professor - aluno - conhecimento criando um novo vértice? Esta última opção é defendida por Albano (2005) que considera que os vértices envolvidos no processo de aprendizagem em e-ensino são quatro: autor, tutor, aluno e conhecimento. O autor neste retângulo didático incorpora as múltiplas funções e personagens que compõem o que chamamos acima de professor coletivo.

Enfatizando a figura do tutor, Albano (2005) o considera um novo elemento, cujas relações autor-tutor, tutor-alunos e tutor-conhecimento são peculiares e têm um papel privilegiado no desenvolvimento do processo. A sua existência como vértice independente no retângulo didático, ou como uma das facetas do professor coletivo pode ser considerada uma questão em aberto, porém o que é ponto pacífico é a importância do tutor no gerenciamento do contrato didático. Como já dissemos 
anteriormente, a ausência da sala de aula retira do processo um local privilegiado para o acompanhamento da relação aluno-saber. Com isto as modificações naturais num contrato didático ditadas pela dinâmica da relação aluno-saber devem ser captadas através de um acompanhamento distinto do tradicional. O tutor tem um papel central neste acompanhamento e no feedback para o professor. Isto indica que o tutor não deve ser apenas um auxiliar no cumprimento de tarefas e atividades, nem apenas um preparador para as avaliações. O tutor deve estar atento à evolução do contrato didático. No ensino a distância, é comum alunos buscarem certa autodidaxia (Belloni e Gomes, 2008). Alunos autodidatas que se fixam nos materiais que se referem apenas a situações didáticas, nem sempre conseguem fazer a ponte com situações adidáticas e não chegam ao significado fundamental. Por exemplo, em cursos de física é comum encontrar alunos de sucesso, limitados apenas aos problemas da física escolar e incapazes de tratar fenômenos outros. A mediação do professor é fundamental neste processo. No ensino a distância, no interior da figura coletiva de professor, tem-se o tutor, que por ter um maior contato com os alunos pode desempenhar um papel importante nesta mediação. Portanto, uma pergunta de investigação pertinente é: Qual o papel do tutor nas modificações no contrato didático que ocorrem com o desenvolvimento da relação alunosaber e principalmente no momento de devolução?

Os tutores têm, comprovadamente, um papel relevante na permanência e sucesso dos alunos, e é essencial identificar seus vários papéis e os conhecimentos, atitudes e habilidades associados. Uma compreensão clara sobre as funções do tutor é essencial para compreender as relações didáticas que se estabelecem entre esse novo ator e os estudantes, e seu papel no contrato didático.

No formato de ensino a distância aqui analisado, o sistema de acompanhamento envolve a participação de dois tipos de tutores. O tutor presencial, chamado tutor polo, responsável por um grupo composto, inicialmente, por 25 a 30 alunos. O tutor a distância, denominado tutor UFSC, se localiza geograficamente na instituição e atua como tutor específico em uma disciplina com a supervisão direta do professor. Os tutores (UFSC e polo) têm formação específica na área do curso. 


\section{O contrato didático e o ensino a distância}

Nesta seção vamos aprofundar um pouco mais a discussão de contrato didático no ensino a distância. O termo foi cunhado por Brousseau (1986) ao discutir as regras que condicionam o funcionamento da educação escolar.

Este contrato organiza e limita as responsabilidades do professor através de um conjunto de regras, em que estão presentes: o compartilhamento de responsabilidades, a consideração do implícito e a relação com o saber. A implantação dessas regras ocorre a partir da primeira aula (Ricardo, Slongo e Pietrocola 2003), na qual um conjunto de regras explícitas e, principalmente, implícitas (resultantes da percepção dos alunos a respeito das expectativas do professor) os leva a reagir desta ou daquela maneira.

Este contrato pode existir somente no interior da relação didática. No ensino presencial, essa relação se dá no interior da sala de aula. Para Balacheff (1988), a aula pode ser definida como uma sociedade costumeira. Esse costume é considerado como um conjunto de práticas e maneiras de agir estabelecidas pelo uso, que rege as relações sociais entre os membros do grupo e, principalmente, esperadas por ele. Desta forma, o costume da aula incorpora as regras (implícitas e explícitas) e os códigos de funcionamento do grupo na relação didática. Portanto, o costume da aula tem um papel fundamental na dinâmica e nas modificações do contrato estabelecido.

No ensino presencial, o costume da aula é estabelecido, entre o professor e o grupo, na sala de aula, portanto, com uma localização no espaço e tempo bem definida. Porém, no ensino a distância não existe esta localização, ao menos de forma constante. Muitas vezes, os contatos se dão no espaço virtual, em momentos definidos por condições diversas vezes fortuitas, sem a presença ou controle de alguns dos membros do grupo, sem a presença simultânea de todos os alunos e, frequentemente, na ausência do professor. Deste modo, torna-se pertinente questionar se há algo que corresponda ao costume da aula, ou o que é estabelecido em seu lugar?

No ensino a distância, a localização e a temporalidade se tornam conceitos mais fluídos. No caso semipresencial, que motivou nossas reflexões, as relações pessoais e interpessoais se estabelecem na atividade escolar. Os professores têm contato presencial 
e ministram aulas apenas uma ou duas vezes, mas os alunos têm encontros regulares para realização de atividades nos polos com tutores. A plataforma de comunicação, isto é, o ambiente virtual de aprendizagem, possibilita videoconferências, chats, fóruns, blogs, criação de wikis além de conversas diretas via Skype. Tudo isto configura um cenário no qual as relações didáticas se realizam e os vários papéis desempenhados pelas várias personalidades envolvidas se manifestam, conformando o conjunto de atividades em que as características implícitas e explícitas do contrato didático são estabelecidas. $\mathrm{Na}$ forma como os estudantes usam o material didático (desenvolvido pela entidade coletiva), o ambiente virtual de aprendizagem, as videoconferências, os chats, fóruns os eventos nos polos criam o cenário e o costume, isto é, o lócus onde uma sociedade costumeira no sentido de Balacheff pode se concretizar em torno das relações didáticas. Parece-nos que, apesar de tantas mudanças, o triângulo didático professor-aluno-saber continua sendo central, embora tenhamos agora que considerar o professor como uma figura múltipla e incorporemos nesta figura o tutor. Isto é, embora outros personagens (aqui considerados facetas do professor) estejam em cena e participem ativamente do processo, permanece invariante a figura do professor que tem uma relação diferenciada com o saber e que é o principal responsável pela escolha de situações didáticas e pela transposição. O professor também é o avaliador, aquele que define o que é o saber e quem "sabe". O cenário e a sociedade costumeira que se formam em torno dele influenciam, sobretudo, as interações mútuas entre os vértices do triângulo didático. 0 contrato didático que se estabelece também possui regras explícitas e implícitas, mas a sua dinâmica é diferente. A ausência da sala de aula implica num peso maior das regras explícitas do contrato, que se manifestam fortemente nos materiais didáticos, na exposição de objetivos, nos pesos dados pelas avaliações, pelas tarefas, etc.. As flexibilizações e mudanças no contrato vão depender fortemente do cenário, da trama construída e do lugar na trama para o momento de devolução e projeção de situações adidáticas. Este cenário é o ambiente no qual as manifestações do costume se estabelecem e nos interessa nesse cenário compreender, no processo ou trama, os papéis que os diferentes personagens desempenham na criação do costume, e, através disto, compreender este novo contrato didático. 
Por exemplo, em algumas modalidades de ensino a distância, periodicamente, ocorrem atividades presenciais nos polos, orientadas por tutores. Este contexto permite levantar questões para investigação tais como: qual o papel destas atividades e do tutor no estabelecimento das regras implícitas e explícitas do contrato didático? Isto se dá em harmonia com o professor e ou de forma diferenciada? Como estas atividades interferem na relação aluno-saber e na relação aluno-professor?

\section{A caracterização dos contratos didáticos}

Segundo Jonnaert e Borght (1999), um contrato didático pode ser caracterizado através de sua: localização na relação didática; ação sobre as mudanças nas relações com os saberes; inserção no tempo; influência na zona de desenvolvimento proximal e influência nas relações didáticas.

Nesta seção vamos explicitar como as diferenças presentes nas modalidades podem influir na maneira como estas características se apresentam.

a) Sua localização na relação didática

Conforme salientado anteriormente, um contrato didático pode ter existência apenas no contexto de uma relação didática, que, na forma tradicional de ensino, é constituída de um conjunto de trocas entre os alunos, o saber e o professor na sala de aula. O gerenciamento dessa relação não se dá através de um conjunto de regras definitivas, mas através de uma série de rupturas, que são necessárias para permitir que cada um dos parceiros modifique suas relações com o saber e com os conhecimentos. $O$ dinamismo desta relação didática é devido às relações assimétricas com o saber. De um lado, um professor que "detém” o saber e do outro, um aluno que o almeja.

No ensino a distância, as trocas entre aluno-saber-professor não ocorrem em sala de aula. Apesar de falarmos em ação compartilhada e professor coletivo, a figura do professor continua tendo um papel central no novo contrato didático, e no que diz respeito à sua relação com o saber não difere essencialmente da modalidade presencial. Porém, a localização do professor na relação didática é mais complexa, pois a ausência da 
sala de aula exige outras formas de acompanhar a dinâmica do processo em que flexibilizações, rupturas e mudanças são ditadas pelas transformações da relação alunosaber. Na ausência da sala de aula, o acompanhamento e gerenciamento desta dinâmica são, necessariamente, ações compartilhadas, nas quais o tutor tem um lugar de destaque.

O tutor desempenha um papel importante na dinâmica do contrato, porém, não é clara, qual a imagem que os alunos associam ao tutor. O tutor pode ser identificado completamente com a figura do professor, no que se refere ao domínio do conhecimento, gerando com o professor uma espécie de persona única. Em outros casos, uma "escala de valor" estabelecida pelos alunos pode situar o tutor como uma figura intermediária que também deve ser superada no processo de quebra da assimetria. Por fim, pode existir ainda a possibilidade de que o tutor seja integralmente identificado como um parceiro mais experiente que caminha ao lado no processo de quebra da assimetria. Cada uma destas possibilidades e sua localização nas relações didáticas merecem uma investigação mais aprofundada.

b) Sua ação sobre as mudanças das relações com os saberes

O professor e o aluno certamente possuem posições assimétricas em suas respectivas relações com o saber, pois o professor enquanto tal é sempre considerado como aquele que tem o domínio sobre o saber, o que significa que ele não apenas "sabe" mais do que o aluno, como tem a responsabilidade de organizar situações de ensino tidas como favoráveis para a aprendizagem, de julgar o que deve ser aprendido, quem aprendeu e assim estabelecer as regras explícitas e implícitas. O conflito e tensão, gerados por esta assimetria, são considerados fundamentais na dinâmica do processo de aprendizagem, influenciando a relação dos alunos com o saber.

Neste contexto, podemos observar que as relações professor-aluno e aluno-saber estabelecem uma dinâmica que pode ser aproximada por duas etapas. Na primeira, a imagem do professor como definidor do saber predomina e o aluno formula questões para decifrar o que o professor considerará válido em seu julgamento. Nesta etapa, o aluno vê o saber como o que é definido pelo professor e se relaciona predominantemente com o mesmo e indiretamente com o saber. Numa segunda fase, o 
aluno formula questões sobre o saber, e o professor passa a ser visto como um mediador. Ao longo deste processo, espera-se que o aluno modifique sua relação com o saber indo em direção a uma relação mais autônoma com o mesmo. Ao longo deste processo, o contrato didático se estabelece e se modifica regendo e sendo regido pela dinâmica das relações.

No ensino presencial, a sala de aula é um local privilegiado para o desenvolvimento desta dinâmica. No ensino a distância, a relação didática é desenvolvida em grande parte através do ambiente (com as videoconferências, fóruns e chats) e, através dos encontros presenciais com professores e tutores. Deste modo, as regras explícitas do contrato ficam claras para os alunos através do plano de ensino da disciplina apresentado pelo professor ou pelo tutor, presencialmente ou de forma virtual através do ambiente. A distância física do professor, e a inserção do tutor na relação fazem, no entanto, com que as regras implícitas sejam mais complexas tornando mais difíceis sua percepção e seu estabelecimento pelo aluno. Apesar disto, um conjunto de regras é decodificado pelo aluno através da relação estabelecida entre o professor e o material didático (livro texto e notas de aula), das avaliações (provas e atividades), da comunicação virtual, dos encontros presenciais (apesar destes encontros não fornecerem profundidade a estas regras) e do contato entre o professor-tutor e tutor-aluno. A decodificação destas regras é também um ato coletivo e depende da interação entre alunos e entre alunos e tutores, entre alunos e professores. Todo este cenário, e personagens envolvidos na dinâmica do contrato didático merecem uma maior investigação.

A ausência da sala de aula estabelece um distanciamento físico e um menor contato presencial entre o professor e o aluno. Este distanciamento físico pode ou não se transformar num distanciamento da relação de mediação. Se isto ocorrer, pode afetar de forma significativa as interações didáticas. O distanciamento do professor pode cristalizar a assimetria e levar os alunos a ressignificá-la associando-a uma noção de intangibilidade. O distanciamento do processo pode levar o aluno a lidar com sua relação com o saber de forma solitária. É importante observar que este mecanismo também pode ocorrer no ensino presencial, uma vez que a presença física do professor não é sinônimo de presença psicológica, e/ou afetiva, e/ou de mediação. Assim, no ensino a distância o contrato 
didático não pode ser apenas o estabelecimento de normas explícitas no planejamento e na designação de atividades e tarefas. A sua localização nas relações didáticas depende das formas de acompanhamento da dinâmica do contrato, e esta atividade envolve a ação compartilhada do professor com outros membros, na qual o tutor desempenha um papel importante.

Desta maneira, uma investigação sobre o ambiente, as formas como as avaliações são realizadas, os papéis do professor e do tutor na organização das situações de ensino e aprendizagem, podem clarear o cenário e o costume, indicando como se inserem neste contexto os diversos agentes da relação (professores, tutores, alunos e saber).

c) Sua inserção no tempo

A relação didática evolui no tempo e termina no final do curso. Porém, a relação estabelecida entre o aluno e o saber avança muito além.

Segundo Vergnaud (1983), uma dupla escala temporal deve ser utilizada na análise do processo de construção do conhecimento. A primeira, denominada escala temporal curta, está relacionada à evolução das práticas e das concepções de um aluno confrontado com uma situação didática no momento durante o qual tem uma fraca relação com o saber (geralmente corresponde ao momento do curso). A segunda, chamada escala temporal longa, corresponde ao tempo de desenvolvimento dos conhecimentos pelo indivíduo, estende-se por vários anos e desenvolve-se muito além da relação didática.

Na sala de aula, o professor, durante a sua mediação, controla o tempo presente e futuro, uma vez que conhece a importância dos conteúdos discutidos, possibilitando idas e vindas durante o processo. Durante a escala curta são criadas situações que fornecem aos alunos instrumentos para o gerenciamento de outras situações.

No ensino a distância, na escala curta, as avaliações marcadas pelo professor gerenciam o tempo nos diferentes momentos do curso. Mas, a falta de aulas obriga o aluno a gerenciar seu tempo de estudo, tornando este gerenciamento temporal mais compartilhado. As interações alunos-tutores e alunos-alunos podem criar mecanismos de gerenciamento mais coletivos, influenciando o cenário e criando costumes e que podem 
influenciar a dinâmica do contrato didático.

Isto pode exigir uma busca de maior autonomia pelo aluno em relação à figura do professor, proporcionando mudanças na dinâmica do contrato didático. Deste modo, uma investigação sobre este compartilhamento do gerenciamento temporal pode fornecer dados que permitam decodificar o cenário e seu costume.

d) Sua influência na zona de desenvolvimento proximal

Segundo Jonnaert e Borght (1999), a abordagem da dupla dimensão temporal na aquisição de conhecimentos pode estar estritamente associada ao conceito de zona de desenvolvimento proximal.

Para Vygotsky (2008), a aprendizagem dá origem a uma série de processos de desenvolvimento internos que, em um determinado momento, apenas são acessíveis ao aluno no quadro da comunicação com o adulto e com os colegas (fase que pode estar associada à escala temporal curta). Estes processos futuramente se transformarão em aquisições, portanto, as interações com colegas e com o professor são fundamentais no processo de aprendizagem.

Neste contexto, ele definiu a zona de desenvolvimento proximal como a diferença entre o nível de resolução de problemas com ajuda de um adulto, no caso das situações escolares, o professor, e o nível de resolução de problemas, atingido sozinho.

No que concerne à zona de desenvolvimento proximal, o desenvolvimento da autonomia ocorre no bojo da interação aluno-professor, aluno-aluno e aluno-saber. Na forma tradicional considera-se que o desenvolvimento desta autonomia é possível quando mediada pelo professor, e pelo ambiente escolar. Na sala de aula, a interação é maior com o professor e os demais ambientes favorecem a interação entre os alunos. No curso a distância a não presença total ou parcial do professor e o compartilhamento da ação pedagógica com os tutores modifica a interação professor-aluno. Por outro lado, a inexistência de uma estrutura física do ambiente escolar pode implicar no distanciamento ou mesmo isolamento dos alunos afetando o grau de interação entre eles. Investigar o papel dos polos e do ambiente virtual no estabelecimento destas interações é fundamental. 
Por outro lado, os alunos de cursos a distância são, desde o princípio, obrigados a agir mais autonomamente. Porém, devemos qualificar esta autonomia, como uma autonomia de ação no sentido que sem a sala de aula o gerenciamento do tempo, local e das tarefas é ditado muito mais pelo próprio aluno. Esta autonomia deve ser diferenciada da autonomia de conhecimento. Isto é, a autonomia de ação não significa que o aluno esteja se instrumentalizando e evoluindo no seu aprendizado, podendo ser uma autonomia ditada apenas pelo isolamento. Segundo alguns críticos do ensino a distância, a autonomia de ação é um obstáculo para aprendizagem e para outros é exatamente uma das molas motoras. A transformação de uma autonomia de ação, em autonomia de conhecimento esta ligada à zona de desenvolvimento proximal, que aqui pode ser pensada como uma busca pela unificação destas duas autonomias. Neste ponto, é fundamental pensar a interação social dentro do contexto do ensino a distância. Aqui, podemos resgatar o conceito de cenário e seu costume, pois em lugar da sala de aula, o cenário é crucial na mediação dos processos que levam ao desenvolvimento de uma autonomia no sentido de Vygotsky. Na versão do curso que estamos tratando, o cenário e seu costume têm como palco o ambiente do polo (ambiente no sentido espaço temporal, considerando não apenas o local físico, mas os diversos momentos de encontro presencial dos alunos, tutores e professores) e o ambiente virtual (que relativiza os conceitos de espaço-tempo, visto que estabelecem novas formas de interação síncronas e assíncronas que podem ter caráter mandatório ou voluntário).

$\mathrm{Na}$ análise do cenário ou da sala de aula deve-se qualificar o processo de interação levando-se em conta a distância transacional, definida por Bouchard (2002). Deste modo, segundo Oliveira, Rego e Villardi (2007), não basta a presença física do outro para garantir a interação, pois os sujeitos envolvidos, embora fisicamente próximos, podem estar psicologicamente e emocionalmente afastados.

A interiorização dos conhecimentos, necessária para o desenvolvimento da autonomia, é fruto de um processo que envolve a apropriação e significação de conceitos, modelos e instrumentos teóricos. A apropriação e a significação dependem fortemente das interações criadas e geradas através das relações didáticas estabelecidas, que envolvem todos os personagens (alunos, professores, tutores e saber). É importante 
frisar que a apresentação primeira dos instrumentos formais e conceituais necessários é feita pelo professor e/ou livros-textos. A significação vai, no entanto, depender da extensão e utilização destes mesmos instrumentos em diversas situações, o que em geral ocorre através da interação com os outros participantes da relação.

Portanto, a decodificação do cenário e seu costume, passa pela investigação do ambiente, das interações que nele se constituem e conformam a dinâmica das relações didáticas.

e) Sua influência nas relações didáticas

A evolução temporal da relação didática pode ser identificada na descrição dos níveis definidos por Brousseau (1986). Para uma breve explicação destes níveis é necessário comentar as situações de aprendizagem por ele definidas.

A situação será didática quando as ações do professor ocorrem através de atividades para "fazer o aluno aprender" o conteúdo que se tem a intenção de ensinar. 0 aluno apresentará dúvidas que serão discutidas com o professor.

Na situação adidática o aluno é capaz de utilizar o conhecimento adquirido para tratar qualquer atividade do professor. Neste caso ocorre uma transferência de primeiro nível.

Em uma situação não didática, a relação do aluno com o saber é independente dos objetivos do professor. A transferência será de segundo nível quando as aquisições de uma determinada disciplina e/ou corpo de conhecimentos facilitam a aprendizagem em outra disciplina, ou permitam a resolução de certas situações da vida cotidiana. Se estas situações forem complexas, a transferência será de terceiro nível.

Assim, o objetivo das situações propostas pelo professor (sejam didáticas ou adidáticas) é permitir que o aluno utilize o conhecimento adquirido em outros contextos.

O estabelecimento do cenário e seu costume criam situações escolares diferenciadas permitindo o aparecimento de pontos de investigação sobre as situações propostas pelo professor (didáticas e adidáticas). A ausência da sala de aula nesse processo indica a necessidade de uma melhor compreensão do papel do cenário e seu 
costume na dinâmica da evolução dos níveis.

\section{Dinâmica do contrato didático}

Segundo Jonnaert e Borght (1999), os principais motores da dinâmica interna de uma relação didática são as rupturas do contrato didático. Elas ocorrem quando um dos parceiros é confrontado com uma situação paradoxal. Isto ocorre particularmente em situações de resolução de problemas.

Diante de um problema a resolver, o aluno se depara com um obstáculo em sua conduta de resolução. Ele tem a consciência de que este obstáculo é indispensável para o aprendizado, e que o professor conhece as ferramentas necessárias para ultrapassá-lo. Portanto, como recurso, ele pode pedir ao professor para ajudá-lo.

Entretanto, o professor pode através da recusa do auxílio colocar o aluno em uma situação em que ele deve incumbir-se de sua própria evolução (devolução didática).

A ruptura aparecerá quando as situações e estratégias (incluindo a devolução) não são suficientes para permitir que o aluno resolva os problemas colocados. Neste momento, o aluno pede ao professor que reassuma o seu ofício (contra devolução).

No ensino presencial, a relação didática ocorre em sala de aula e os momentos de devolução e contra devolução podem ser administrados pelo professor.

No ensino a distância, o professor, na maior parte do tempo, não está presente. A relação (se estabelecida) ocorre durante a maior parte do tempo no ciberespaço. A mediação é feita através do material didático (livro texto e mídias). Deste modo, o desenvolvimento de instrumentos que permitam a investigação de como ocorrem as rupturas neste processo, que possibilitem a observação e identificação do mecanismo da devolução e contra devolução são importantes.

O entendimento deste mecanismo poderá contribuir para o desenvolvimento de ambientes e metodologias, levando em conta as características desta modalidade de ensino, que permitam maior eficiência no processo e administração destas rupturas por 
parte do professor.

\section{Considerações finais}

Neste trabalho fazemos uma reflexão sobre as novas relações didáticas estabelecidas no ensino a distância. Segundo Jacquinot (1993), o ensino a distância tem como desafio reduzir as distâncias e suprimir as ausências. Este desafio se coloca não apenas devido à necessidade social urgente de novos professores, mas também, pelos novos modos de socialização que surgiram com as novas tecnologias de informação e comunicação e estabelecem novos ambientes de aprendizagem que extrapolam os muros escolares. O ensino a distância é, segundo nossas reflexões, um cenário particular destes novos modos de socialização e aprendizagem. Assim sendo, o ensino a distância pode ser encarado como um laboratório para uma melhor compreensão sobre estas novas formas e relações.

As ausências da sala de aula e da presença física do professor modificam as relações espaço-temporais e levam ao estabelecimento de novas relações didáticas. Neste contexto, a sala de aula deixa de ser o local onde as relações didáticas se desenvolvem, sendo substituída por um cenário. Desta maneira é imprescindível a compreensão dos papéis que os diversos personagens desempenham na criação do que denominamos cenário e seu costume. É importante perceber que neste novo cenário uma sociedade costumeira, no sentido de Balacheff, se estabelece. O estabelecimento de costumes e códigos implícitos e explícitos guia a dinâmica das relações didáticas entre os vários personagens da ação educativa. Em grande parte, é no trabalho de decodificação que reside o processo que deveria guiar o aluno para um aprendizado significativo.

Partindo da noção de contrato didático, levantamos pontos para a investigação de como o cenário e seu costume é estabelecido e decodificado pelos alunos.

O contrato didático gere a assimetria presente na relação didática, fazendo-a evoluir e progredir. No ensino a distância, o dinamismo desta relação é diferente em virtude da pouca presença física do professor. Um dos perigos apontados por críticos 
desta modalidade é a possibilidade desta ausência levar a uma cristalização e/ou ressignificação desta assimetria, associando-a a noção de intangibilidade e/ou mantendoa tão longe do processo que o aluno passa a ter uma relação solitária com o saber. Por outro lado, as novas tecnologias de comunicação relativizam a distância e o tempo, estabelecendo novas possibilidades de interação professor-aluno. Esta relativização pode ser importante no gerenciamento da assimetria e também no estabelecimento de interações sociais entre os agentes. Os efeitos da introdução destas novas tecnologias de comunicação são partes integrantes do cenário e seus costumes, portanto, devem ser investigados. É importante ainda ressaltar que a presença de um novo parceiro, o tutor, deve desempenhar um papel no gerenciamento desta assimetria. O papel e o peso deste novo parceiro no estabelecimento do cenário e seu costume também deve ser um dos focos de investigação.

Convém lembrar que esta assimetria gera conflitos e tensões que são considerados fundamentais na dinâmica do processo de aprendizagem, influenciando as relações dos alunos com o saber. No ensino a distância, as regras explícitas ficam claras através do plano de ensino, enquanto as implícitas são estabelecidas ao longo da criação da sociedade costumeira. Na ausência da sala de aula, o imaginário dos alunos e as trocas entre os possíveis atores levam ao estabelecimento destas regras de forma diferenciada. Em nosso entendimento, as regras implícitas também podem ser decodificadas através da ênfase e da forma com que o professor trabalha o material didático, das avaliações, da comunicação virtual, dos encontros presenciais e dos tutores, que em suas intervenções junto aos alunos podem deixar estas regras mais claras.

Outro ponto importante que pode caracterizar o contrato didático é o gerenciamento do tempo. No ensino a distância, este gerenciamento é compartilhado entre os diversos agentes, pois enquanto avaliações marcadas pelo professor determinam uma escala temporal para o curso, o gerenciamento do tempo de estudo fica a cargo do aluno. Dependendo das relações estabelecidas entre alunos e tutores, e entre os próprios alunos, pode haver uma busca maior pela conquista de uma autonomia, o que tem implicações na dinâmica do contrato estabelecido.

Esta autonomia deve ser, a princípio, qualificada como uma autonomia de ação, no 
sentido que ela está relacionada ao gerenciamento do tempo, e não necessariamente a uma instrumentalização e evolução no aprendizado. A transformação da autonomia de ação em uma autonomia de conhecimento está relacionada à zona de desenvolvimento proximal, o que enfatiza a importância da interação social no contexto do ensino a distância. Na versão do curso discutida neste trabalho, o cenário e seu costume são estabelecidos no polo e no ambiente virtual, desta maneira uma investigação do ambiente e das interações, que neles se constituem, é fundamental na dinâmica da relação didática.

Jonnaert e Borght (1999) ainda afirma que os principais motores da dinâmica interna de uma relação didática são as rupturas do contrato didático. Elas aparecem quando um dos parceiros é confrontado com uma situação paradoxal. No ensino presencial os mecanismos de devolução e contra devoluções didáticas, que permitem gerenciar as rupturas, são administrados pelo professor com forte influência do costume de aula estabelecido. No ensino a distância é importante investigar como estes mecanismos ocorrem e o papel dos tutores neste processo. $O$ entendimento desse mecanismo pode levar ao estabelecimento de ambientes e metodologias que levem em conta as características desta modalidade.

Podemos finalizar afirmando que o ensino a distância é uma modalidade que traz à tona uma série de pontos de investigação sobre as relações didáticas, inserção de novas tecnologias e metodologias no ensino de física. Portanto ela pode ser considerada um objeto importante de pesquisa.

É importante ainda observar que outras universidades utilizam formatos diferentes, sem nenhum contato físico entre professores e alunos, apenas com interações através do ambiente virtual. Apesar das diferenças, acreditamos que em boa parte nossa reflexão seja útil na investigação de novos cenários, costumes e contratos didáticos estabelecidos. 


\section{Referências}

ALBANO, Giovannina. Mathematics and e-learning: a conceptual framework. CERME 4, Sant Felieu de Guíxols, 2005. Disponível em: <hal.archivesouvertes.fr/docs/00/19/03/25/PDF/Giovannina-Albano-2005.pdf.> Acesso em: fevereiro de 2013.

BALACHEFF, Nicolas. Le contrat et la coutume, deux registres des interactions didactiques. In LABORDE, Colette. (dir). Actes du premier colloque Franco-Allemand de didactique des mathemátiques et d'informatique. Grenouble: La Pensée Sauvage, 1988.

BELLONI, Maria Luiza. Educação a distância. Campinas: Autores Associados, 2002.

BELLONI, Maria Luiza e GOMES, Nilza Godoy. Infância, mídias e aprendizagem: autodidaxia e colaboração. Educ. Soc. Campinas, v. 29, n. 104 - Especial, p. 717 - 747, out. 2008.

BOUCHARD, Paul. Autonomia e distância transacional na formação a distância. In: ALAVA, Séraphin. Ciberespaço e formações abertas: rumo a novas práticas educacionais? Porto Alegre: Artmed, 2002.

BROUSSEAU, Guy. Fondaments et méthods de la didactique des mathemátiques. Recherches en Didactique des Mathemátiques, v.7, n. 2, 1986.

JACQUINOT, Geneviève. Apprivoiser la distance et supprimet l'absence? Ou le défis de la formation à distance. Revue Française de Pédagogie, n. 102, jan./ mar., p.55 - 67. 1993

JONNAERT, Philippe. \& BORGHT, Cécile. Vander. Criar condições para aprender. Porto Alegre: Artmed Editora, 1999.

KEEGAN, Desmond. On Defining Distance Education. In: SEWART, David. et al (eds.), Distance education: international perspectives. Londres; Nova Iorque: Cromhelm/ St. Martin's, 1983.

LITWIN, Edith. Temas em debate em torno de la educación a distancia em las universidades públicas argentinas. In: LITWIN, Edith.; MAGGIO, Mariana.; ROIG, Hebe. Educación a distancia em los 90: desarrollos, problemas y perspectivas. Buenos Aires: Facultad de Filosofia y Letras (UBA) y Programa UBA XXI, 1994.

MAGGIO, Mariana. O tutor na educação a distância. In: LITWIN, Edith. Educação à distância: temas para o debate de uma nova agenda educativa. Porto Alegre: Artmed Editora, 2001. 
OLIVEIRA, Eloisa da Silva Gomes., REGO, Marta Cardoso Lima C. e VILLARDI, Raquel Marques. Aprendizagem mediada por ferramentas de interação: análise do discurso de professores em um curso de formação continuada a distância. Educação \& Sociedade, v. 28, n. 101, p. $1413-1434,2007$.

RICARDO, Elio; SLONGO, Ione; PIETROCOLA, Maurício. A Perturbação do contrato didático e o gerenciamento dos paradoxos. Investigação em Ensino de Ciências, v. 8, n. 2, p. $153-163,2003$.

VERGNAUD, Gérard. Didactique et acquisition du concept de volume. Recherches em didactique des mathematiques, v. 4, n. 1, p. $9-25,1983$.

VYGOTSKY, Lev Semyonovich. A Formação social da mente. São Paulo: Ed. Martins Fontes, São Paulo, 2008.

Recebido em: 25/03/2013 Aprovado em: 18/09/2013

Universidade do Estado de Santa Catarina - UDESC Programa de Pós-Graduação em Educação - PPGE Revista Linhas Volume 15 - Número 28 - Ano 2014 revistalinhas@gmail.com 